\title{
Systemic inflammation and skeletal muscle dysfunction in chronic obstructive pulmonary disease: state of the art and novel insights in regulation of muscle plasticity
}

Citation for published version (APA):

Remels, A. H., Gosker, H. R., van der Velden, J. L., Langen, R. C., \& Schols, A. M. (2007). Systemic inflammation and skeletal muscle dysfunction in chronic obstructive pulmonary disease: state of the art and novel insights in regulation of muscle plasticity. Clinics in Chest Medicine, 28(3), 537-552. https://doi.org/10.1016/j.ccm.2007.06.003

Document status and date:

Published: 01/01/2007

DOI:

10.1016/j.ccm.2007.06.003

Document Version:

Publisher's PDF, also known as Version of record

\section{Document license:}

Taverne

\section{Please check the document version of this publication:}

- A submitted manuscript is the version of the article upon submission and before peer-review. There can be important differences between the submitted version and the official published version of record. People interested in the research are advised to contact the author for the final version of the publication, or visit the DOI to the publisher's website.

- The final author version and the galley proof are versions of the publication after peer review.

- The final published version features the final layout of the paper including the volume, issue and page numbers.

Link to publication

\footnotetext{
General rights rights.

- You may freely distribute the URL identifying the publication in the public portal. please follow below link for the End User Agreement:

www.umlib.nl/taverne-license

Take down policy

If you believe that this document breaches copyright please contact us at:

repository@maastrichtuniversity.nl

providing details and we will investigate your claim.
}

Copyright and moral rights for the publications made accessible in the public portal are retained by the authors and/or other copyright owners and it is a condition of accessing publications that users recognise and abide by the legal requirements associated with these

- Users may download and print one copy of any publication from the public portal for the purpose of private study or research.

- You may not further distribute the material or use it for any profit-making activity or commercial gain

If the publication is distributed under the terms of Article $25 \mathrm{fa}$ of the Dutch Copyright Act, indicated by the "Taverne" license above, 


\title{
Systemic Inflammation and Skeletal Muscle Dysfunction in Chronic Obstructive Pulmonary Disease: State of the Art and Novel Insights in Regulation of Muscle Plasticity
}

\author{
Alexander H. Remels, MSc, Harry R. Gosker, PhD, \\ Jos van der Velden, BSc, Ramon C. Langen, PhD, \\ Annemie M. Schols, PhD* \\ Department of Respiratory Medicine, Nutrition and Toxicology Research Institute, University of Maastricht, \\ P.O. Box 5800, 6202 AZ Maastricht, The Netherlands
}

Chronic obstructive pulmonary disease (COPD) is a chronic lung disease characterized by at least partially irreversible airway obstruction and an abnormal chronic inflammatory response of the airways. Dominant symptoms are dyspnea and impaired exercise capacity. These symptoms lead to progressive disability and poor health status but correlate poorly with severity of local impairment in the lungs. Surprisingly, even in the most recent international guidelines for diagnosis of COPD, staging is still based on severity of airways obstruction only. There is increasing evidence in the literature that COPD should not be considered a localized pulmonary disorder but a systemic disease that involves pathology in several extrapulmonary tissues. Well-characterized systemic features include chronic low-grade systemic inflammation and altered regulation of protein metabolism, which result initially in muscle atrophy only (commonly referred to as sarcopenia) but in later stages also result in cachexia [1,2].

Muscle atrophy is associated with increased mortality risk independent of disease staging based on severity of airflow obstruction [3]. Besides muscle atrophy, it is well established that intrinsic abnormalities in muscle structure and metabolism are present in moderate to severe cases of COPD and that both processes contribute

\footnotetext{
* Corresponding author.

E-mail address: schols@pul.unimaas.nl(A.M. Schols).
}

to reduced strength and endurance of the muscle. In turn, skeletal muscle dysfunction adversely affects clinical outcome in COPD, because it is an independent determinant of exercise limitation $[4,5]$. In this article we present a state-of-the-art update on skeletal muscle dysfunction and systemic inflammation in patients who have COPD and discuss the therapeutic potential of novel insights from experimental research in the regulation of muscle plasticity.

\section{Characterization and causes of skeletal muscle dysfunction in chronic obstructive pulmonary disease}

Skeletal muscle dysfunction in COPD is characterized by a reduction in strength and endurance of the muscle. Skeletal muscle strength is largely determined by muscle mass. Data clearly indicate that atrophy of skeletal muscles is apparent in COPD and that the disease selectively affects the predominant glycolytic type IIA/IIX fibers [6,7]. Loss of muscle mass is a complex process that involves changes in the control of substrate and protein metabolism and changes in muscle cell turnover. Impaired protein metabolism may result in muscle atrophy when protein degradation exceeds protein synthesis. To date, a limited number of studies have addressed protein metabolism in patients who have COPD. Using stable isotope techniques, two studies have 
investigated muscle protein turnover in patients who have COPD. Morrison and colleagues [8] demonstrated a decreased muscle protein synthesis in underweight patients with emphysema. More recently, Rutten and colleagues [9] showed an elevated myofibrillar protein breakdown in cachectic patients who had COPD, whereas no difference was seen between noncachectic patients who had COPD and healthy controls. At the cellular level, increased apoptosis of muscle cells has been demonstrated in skeletal muscle of severely underweight patients who have COPD [10], although this observation was not confirmed in weight-stable patients who have COPD and are suffering from muscle wasting [11]. This finding could implicate different mechanisms in loss of muscle mass in the absence or presence of weight loss (ie, sarcopenia versus cachexia).

Reduced muscle endurance, on the other hand, is not associated with muscle wasting but may be secondary to either intrinsic muscle alterations (mitochondrial abnormalities and loss of contractile proteins) or alterations in the external milieu in which the muscle works (hypoxia, hypercapnia, and acidosis) that result from the abnormalities of pulmonary gas exchange that exist in COPD. Gosker and colleagues [12] showed that in COPD there is a shift in muscle fiber type from type I (slow twitch, oxidative fibers) to type II (fast twitch glycolytic) fibers. Type I fibers are resistant to fatigue, whereas type II fibers are more fatigable. A decrease in the percentage of type I fibers in the vastus lateralis of patients who have COPD compared with age-matched controls was reported together with a corresponding increase in type IIx fibers [12]. Research has shown consistently that peripheral muscles of patients who have COPD are characterized by reduced activities of enzymes involved in muscle oxidative metabolism as citrate synthase and $\beta$-hydroxyacylCoA dehydrogenase $[12,13]$. Conversely, activities of glycolytic enzymes were found to be increased in lower limb muscle of patients who have COPD by some studies [13]. Because these enzyme activities depend largely on fiber type [14], it is likely that this shift in activities is related to the shift in fiber distribution mentioned previously. Whether enzyme activities adapt to the fiber type or the other way around remains unclear.

Further indication of an impaired energy metabolism in patients who have COPD is derived from studies that measured substrate and cofactor concentrations in peripheral skeletal muscle of patients who have COPD. Most striking was the observation of reduced concentrations of high-energy phosphates at rest, as indicated by elevated levels of inosine monophosphate [15]. Muscle glycogen content in COPD also tends to be lower, whereas lactate concentrations are higher than in healthy persons [16,17]. These data indicate that anaerobic energy metabolism is enhanced in COPD. Because this process yields far less ATP than complete oxidative degradation of glucose, a reduced energy state in COPD could not only limit exercise endurance but also contribute to a decreased work efficiency that has been reported during cycle exercise [18] and elevated energy expenditure in some patients [19]. We hypothesized that uncoupling protein 3 (UCP-3), which uncouples oxidative phosphorylation from ATP production, is implicated in the elevated energy expenditure in COPD. Gosker and colleagues [20], however, demonstrated that instead of the expected increase in skeletal muscle UCP-3 content, UCP-3 protein levels were decreased in skeletal muscle of patients who have COPD. UCP-3 also has been postulated as an important factor in the defense against lipid-induced oxidative muscle damage [21]. Markers of oxidative stress are elevated in skeletal muscle of patients who have COPD at rest and during exercise [22]. Consequently, impaired skeletal muscle antioxidant defenses also have been reported [23].

\section{Characterization and sources of systemic inflammation in chronic obstructive pulmonary disease}

By definition, COPD is a disorder characterized by reduced maximum expiratory flow and slow forced emptying of the lungs caused by varying combinations of diseases of the airways and emphysema. Progression of the disease is associated with an intense chronic inflammation of the lungs, and the critical role of this local inflammatory process in the pathogenesis and progression of COPD is generally recognized and accepted. In addition to airway inflammation, there is increasing evidence of low-grade systemic inflammation in COPD. In contrast to extensive knowledge of the inflammatory process in the airways of patients who have COPD, surprisingly less is known about systemic inflammation in this disorder. Although the exact relationship between inflammation in the lung and in the systemic compartment remains to be established, an inverse relationship has been shown between the presence of systemic inflammation and the mean forced expiratory volume in 1 second in patients, which 
highlights the importance of systemic inflammation in disease progression [24].

According to a recent meta-analysis, several clinical studies have reported persistent systemic inflammation in COPD, as evidenced by elevated levels of the proinflammatory cytokines tumor necrosis factor-alpha (TNF- $\alpha$ ), interleukin-6 (IL-6), IL-8, and the soluble TNF- $\alpha$ receptors (sTNFR-55 and sTNFR-75) $[25,26]$. Proinflammatory cytokines such as IL- 6 and TNF- $\alpha$ have been shown to induce the formation of acute phase reactants. One of the major acute phase proteins, C-reactive protein, is increased in the circulation of patients who have COPD compared to healthy controls [27]. High C-reactive protein levels in the circulation of patients who have COPD have been associated with reduced quadriceps strength, lower maximal and submaximal exercise capacity, and increased mortality [28,29].

The origin of the systemic inflammation in patients who have COPD remains poorly understood; several (independent) pathways may be involved. Although a relationship between lung and systemic inflammation has been suggested, evidence from available cross-sectional studies indicates no clear correlation between the presence of inflammation in the pulmonary and systemic compartments [30]. This finding suggests that the systemic inflammatory response is not caused by an overflow of inflammatory mediators from the pulmonary compartment but is regulated differently. Potential nonpulmonary sources of systemic inflammatory mediators include inflammatory cells in the circulation, because several studies have shown increased levels of various circulating inflammatory cells, including neutrophils and lymphocytes, in peripheral blood of patients who have COPD. The activation of peripheral blood lymphocytes, which results in potentiation of cytotoxic and migratory responses, also has been shown [31].

A second pathway involved in the process of systemic inflammation could be hypoxia, which is often present in patients who have severe COPD. Several in vitro studies have shown that hypoxia results in enhanced cytokine production by macrophages, which could contribute to activation of the TNF- $\alpha$ system in COPD. Takabatake and colleagues [32] showed a significant inverse relationship between arterial oxygen pressure and circulating levels of TNF- $\alpha$ and soluble TNF-R in patients who have COPD. Alternatively, increased levels of inflammatory mediators in the blood of patients who have COPD may originate from muscle cells or yet-unexplored extrapulmonary cells, including endothelium and fat tissue. Skeletal muscle itself is capable of constitutive and inducible production of proinflammatory cytokines, such as TNF- $\alpha$ and IL-6 $[33,34]$. Data on the contribution of extrapulmonary cells to the ongoing inflammatory process in COPD is, to date, lacking.

Several studies have shown that systemic inflammatory cytokines, such as TNF- $\alpha$ and IL- 6 , are proximal markers of cachexia and selectively target myosin protein content in skeletal muscle. High levels of IL-6 have been associated with reduced quadriceps strength and diminished exercise capacity [29], and TNF- $\alpha$ has been shown to be inversely related to muscle mass [35]. These cytokines may cause skeletal muscle weakness without causing muscle wasting by directly compromising contractile properties of the skeletal musculature. De Oca and colleagues [36] showed that TNF- $\alpha$ protein levels in skeletal muscle of patients who have COPD were markedly higher compared to healthy control subjects. A study by Agusti and colleagues [37] also suggested that patients who have severe COPD and are suffering from weight loss are characterized by increased activation of the transcription factor nuclear factor kappa B (NF- $\kappa$ B), a major signaling pathway that conveys inflammatory signals, in skeletal muscle.

These studies indicated that the systemic inflammatory process in COPD also involves the skeletal musculature itself. Although recent studies showed a clear association between C-reactive protein and impaired muscle function and exercise capacity, even after adjustment for mean forced expiratory volume in 1 second, it is unclear if this association is linked to effects on muscle mass or caused by direct effects on muscle contractility [38]. In summary, a large body of evidence suggests that systemic inflammation is present in patients who have COPD, and several lines of evidence indicate a significant role of inflammatory mediators in disturbed regulation of muscle mass and muscle functional capacity. Because most data in this context originated from studies with a cross-sectional design, longitudinal studies are needed to unravel the exact role of systemic inflammation in the progression of COPD and the impairment of skeletal muscle function.

\section{Novel insights in the regulation of muscle mass during muscle wasting}

Abundant evidence from in vitro research and experimental models indicates that inflammatory 
stimuli trigger weight loss and muscle atrophy [35,39-41]. Muscle loss has been documented in animals treated with exogenous TNF- $\alpha$, in animals that express a TNF transgene, and in diseases that elevate endogenous TNF- $\alpha$ (ie, experimental sepsis or tumor implantation) [41]. Several studies also point to the importance of IL- 6 in the regulation of muscle wasting [35,42]. Little information is available, however, on how elevated and circulatory levels of inflammatory mediators, such as TNF- $\alpha$ and IL- 6 , convey signaling cues that cause skeletal muscle to atrophy. Upon binding to their cognate receptors at the myofiber surface, proinflammatory cytokines, such as TNF- $\alpha$ and IL-1 $\beta$, cause activation of the transcription factor $\mathrm{NF}-\kappa \mathrm{B}$. Under basal conditions, NF- $\kappa \mathrm{B}$ is present within the cytoplasm in an inactive state, bound to its inhibitory protein $\mathrm{I} \kappa \mathrm{B} \alpha$. Upon stimulation with an inflammatory stimulus (eg, TNF- $\alpha$ ) an intracellular signaling cascade is initiated, which results in the phosphorylation of $\mathrm{I} \kappa \mathrm{B} \alpha$ by $\mathrm{I} \kappa \mathrm{B}$ kinase and subsequent degradation of $I \kappa B \alpha$. Once liberated from its inhibitory protein, NF- $\kappa \mathrm{B}$ translocates into the nucleus, where it regulates transcription of various inflammatory genes [43]. Although the intracellular signaling initiated by inflammatory stimuli is certainly not limited to $\mathrm{NF}-\kappa \mathrm{B}$ activation in skeletal muscle, recent work suggests that this pathway is involved in muscle atrophy signaling.

The exact intracellular mechanisms responsible for inflammation-induced wasting of skeletal muscle remain to be elucidated. At the protein level, an imbalance between protein synthesis and protein degradation may favor muscle catabolism. At the cellular level, a disturbed balance between the loss and gain of nuclei in muscle fibers through apoptosis and myonuclear accretion, respectively, may contribute to loss of skeletal muscle mass. These processes are discussed in further detail later in this article. Importantly, these processes are not mutually exclusive but are likely to occur in parallel during muscle wasting, as has been shown for their involvement in muscle plasticity in response to physiologic stimuli.

\section{Effects of inflammation on regulation of muscle protein turnover}

\section{Protein degradation}

Work using cultured murine myotubes (eg, the in vitro equivalents of muscle fibers) demonstrated that TNF- $\alpha$ directly stimulates a time- and concentration-dependent decrement in total muscle protein content and loss of muscle-specific proteins, including fast-type myosin heavy chain (MyHC). MyHC losses were not accompanied by a change in synthesis rate, which suggests that TNF- $\alpha$ stimulated degradation of myofibrillar proteins rather than inhibited their synthesis $[41,44]$. Research also has demonstrated that infusion with TNF- $\alpha$ increased muscle proteolysis in rats [45]. Several proteolytic systems could contribute to enhanced protein degradation in chronic inflammatory disorders, including the lysosomal pathway, the $\mathrm{Ca}^{2+}$-dependent pathway, caspases, and the ATP-dependent ubiquitin proteasome pathway (UPP). Recent in vitro and animal model-derived evidence postulates the UPP as the predominant pathway involved in skeletal muscle atrophy. In this pathway, proteins to be degraded are tagged by at least four moieties of the polypeptide ubiquitin ( $\mathrm{Ub}$ ), which are covalently bound at the lysine 48 residue. This process, named $\mathrm{K} 48-\mathrm{Ub}$ conjugation, requires the sequential activity of a series of specific enzymes: E1, or Ub-activation enzyme; E2, or Ub-conjugating enzyme; and E3, or Ub-ligase. K48-polyubiquitinated proteins are recognized and degraded by the 26S-proteasome complex into short peptides that are further rapidly degraded to free amino acids in the cytosol [46].

Elevated Ub gene expression and Ub conjugation were reported in skeletal muscle after the administration of TNF- $\alpha$ in vitro [47]. MyHC depletion in response to TNF- $\alpha$ also occurred via an upregulation of certain components of the Ubproteasome pathway [48]. Several in vivo models confirm the involvement of TNF- $\alpha$ and the UPP in wasting of skeletal muscle mass. Increased expression of muscular $\mathrm{Ub}$ and $\mathrm{Ub}$ conjugation were observed in rats after injection of TNF- $\alpha$ [49]. Two muscle-specific Ub (E3) ligases, atrogin-1/MAFbx and MuRF1, also are rate limiting for muscle protein loss in various catabolic conditions. Expression of these two Ub ligases is upregulated in the muscle of various animal models of inflammation-associated muscle atrophy, including cancer, diabetes, and sepsis, whereas the muscle mass of MAFbx-/- and MuRF1-/- gene knockout animals is spared in several of these atrophy models [50-52].

Muscle proteins targeted for degradation by the UPP in response to inflammatory cytokines include MyHC and MyoD [53,54]. MyHC is a myofibrillar protein involved in muscle contraction, whereas MyoD is a muscle regulatory factor 
essential for muscle-specific gene expression and muscle growth implicating a mechanism by which the UPP contributes to muscle atrophy, not only through degradation of specific muscle proteins but also via the selective degradation of regulatory proteins. Several studies have postulated an important role for NF- $\mathrm{KB}$ in this regulation of protein degradation through the UPP during muscle atrophy. For instance, loss of MyHC protein in response to TNF- $\alpha$ corresponded with NF- $\kappa \mathrm{B}$ activation in cultured myotubes, and inhibition of NF- $\kappa \mathrm{B}$ activity blocked cytokine-mediated decreases in muscle-specific proteins [48]. TNF- $\alpha$ increases Ub-conjugating activity in skeletal muscle cells in vitro in an NF- $\kappa \mathrm{B}-$ dependent manner [47]. It was recently established that through musclespecific transgenic expression of activated $\mathrm{I} \kappa \mathrm{B}$ kinase 2, constitutive activation of NF- $\mathrm{B}$ in skeletal muscle was sufficient to induce profound muscle atrophy. Muscle loss in this model was caused by accelerated protein breakdown through Ub-dependent proteolysis, because expression of the E3 ligase MuRF1, a mediator of muscle atrophy, was increased and muscle atrophy was ameliorated in MuRF1-deficient mice [55]. Conversely, skeletal muscle-specific inhibition of NF- $\kappa \mathrm{B}$ activation preserved muscle tissue in various experimental models of muscle atrophy [56], which indicated that muscular NF- $\kappa \mathrm{B}$ activation may be required for the loss of muscle mass in certain (pathologic) conditions.

\section{Protein synthesis}

In addition to increased proteolysis, systemic inflammation is also associated with decreased protein synthesis. Protein synthesis is impaired in muscles of animals subjected to experimental sepsis [57], and this response seems to involve systemic inflammation, because TNF- $\alpha$ and IL- $1 \beta$ antagonists have been reported to improve muscle protein balance in septic rats by preventing decreased synthesis rates $[58,59]$. Conversely, administration of TNF- $\alpha$ or IL- $1 \beta$ reduced synthesis of the major muscle proteins in rats $[59,60]$. Muscle protein synthesis is under positive control of insulin-like growth factor-1 (IGF-1) signaling. Decreased circulating IGF-1 levels have been reported in response to sepsis and IGF-1 resistance of skeletal muscle exposed to inflammatory cytokines [61]. Skeletal muscle production of IGF-1, which stimulates protein synthesis and suppresses degradation in an autocrine fashion, is reduced by inflammatory mediators [61].
Binding of IGF-1 to its receptor initiates a signal transduction cascade that promotes mRNA translation and consequently increases protein synthesis [62]. Incubation of skeletal muscle cells with inflammatory cytokines, including TNF- $\alpha$ and IL- $1 \beta$, induces IGF-1 resistance, which is characterized by decreased protein synthesis as a result of impaired signaling proximal to receptor activation [63]. The exact molecular mechanism of inflammation-induced IGF-1 resistance in skeletal muscle remains to be elucidated but may involve ceramide as an intermediate, because inhibition of de novo synthesis of this second messenger prevented impaired IGF-1-induced protein synthesis by TNF- $\alpha$ or IL-1 $\beta$ [64].

\section{Effects of inflammation on regulation of myonuclear turnover}

Because of its multinucleated nature, the cytoplasm (sarcoplasm) of a myofiber is shared by multiple nuclei, each of which is thought to regulate protein expression for a defined volume of the sarcoplasm (eg, the myonuclear domain). Experimental evidence indicates that the dimensions of the myonuclear domain are relatively constant, implying flexibility of the myonuclear number to accommodate muscle plasticity, which is accomplished by the addition (myonuclear accretion) or loss (by apoptosis) of myonuclei during muscle (fiber) growth and atrophy, respectively [65]. In addition to an inequity in muscle protein synthesis and degradation, an imbalanced myonuclear turnover may contribute to muscle atrophy in patients with disorders associated with chronic inflammation. The effects of inflammatory mediators on cellular mechanisms that regulate apoptosis and myonuclear accretion are described herein.

\section{Apoptosis}

Apoptosis, or programmed cell death, is an important process in multicellular organisms during development but also in postnatal tissue homeostasis. Apoptosis can be initiated by ligand binding to so-called "death receptors" (which include Fas and members of the TNF receptor family) or by the release of apoptosis-inducing factors from mitochondria [66]. Subsequently, protein-cleaving enzymes (caspases) and endonucleases are activated, which results in the degradation of regulatory proteins and DNA fragmentation, respectively. In mononuclear cells, this process ultimately culminates in the 
formation of apoptotic bodies that are cleared by macrophages. Because of the multinucleated nature of myofibers, however, the elimination of one myonucleus by apoptosis is not necessarily followed by the destruction of the entire myofiber, and this process is referred to as apoptotic nuclear death. As a consequence, the mechanisms involved in apoptosis signaling in skeletal muscle are likely distinct from mononucleated cells.

DNA fragmentation that suggests apoptosis has been reported in skeletal muscle of septic rats, which was prevented by administration of a TNF- $\alpha$ antagonist, which suggests that TNF- $\alpha$ may trigger apoptotic events in skeletal muscle during inflammatory conditions [67]. This notion is further supported by experiments in cultured myoblasts and myotubes, which revealed DNA fragmentation after chronic exposure to TNF- $\alpha$ [68], although differentiated myofibers seem to be more resistant to TNF- $\alpha$-induced apoptosis than undifferentiated myoblasts [41]. Myoblasts exposed to TNF- $\alpha$ show procaspase- 8 cleavage [69], whereas TNF- $\alpha$-induced apoptosis in skeletal muscle of patients who have COPD may be mediated by upregulation of inducible nitric oxide synthase in myofibers [37]. Caspase-3 activation was reported to contribute to myofibrillar protein degradation in catabolic conditions [70] and was associated with muscle weakness in sepsis [71]. In chronic heart failure, circulatory levels of TNF- $\alpha$ are increased, which is paralleled by a rise in the number of apoptotic nuclei in the soleus and tibialis anterior muscles [72]. Despite these recent studies suggesting a role of TNF- $\alpha$ and other inducers and mediators of apoptotic signaling in skeletal muscle atrophy, the relevance of these pathways in myofibers remains to be established because of their multinucleated nature and potential cell death-unrelated consequences.

\section{Myonuclear accretion and muscle regeneration}

During conditions such as muscle growth, recovery from atrophy, and muscle regeneration after damage, myonuclear accretion is increased, which requires activation of local muscle precursor cells, called satellite cells $[65,73]$. Upon activation, these cells proliferate to form a pool of myoblasts, which differentiate to fuse with existing myofibers or form new myofibers, processes that are essential for efficient muscle growth, regrowth, and regeneration [74]. Several groups have demonstrated that TNF- $\alpha[40,75]$ and the related ligand TWEAK [76] as well as IL-1 $\beta$ inhibit muscle differentiation and myoblast fusion $[75,77]$. Inhibition of myogenesis by TNF- $\alpha$ requires activation of NF- $\mathrm{KB}$ and involves repression of MyoD synthesis and protein stability [78]. MyoD is a master regulator of myogenesis, which explains the inability of myoblasts to express muscle-specific gene transcripts or form multinucleated myotubes in the presence of these proinflammatory cytokines. Recent evidence also showed that TNF- $\alpha$ could inhibit myogenesis through the activation of caspases [79]. In a model of chronic pulmonary (and systemic) inflammation, impaired muscle differentiation and regeneration was observed during muscle regrowth after atrophy [35]. These data indicated that inflammatory signaling may impair muscle differentiation and myonuclear accretion, thereby compromising the ability of the muscle to recover after injury or atrophy and contributing to the loss of muscle mass observed in several inflammatory conditions.

To conclude, the effects of inflammation on the regulation of muscle mass may favor muscle atrophy as a result of imbalances in protein turnover and myonuclear turnover and likely involve enhanced myofibrillar protein degradation and/or reduced protein synthesis and activation of apoptotic mechanisms and/or impaired myonuclear accretion. These processes are summarized in Fig. 1.

\section{Novel insights in the regulation of fiber type and muscle oxidative phenotype}

One of the most prominent features of skeletal muscle is its high level of plasticity. Physical activity level, nutritional status, and the presence and/or absence of disease are important factors determining muscle mass, fiber type composition, and oxidative capacity. The muscle senses these factors as mechanical, metabolic, neuronal, or hormonal stimuli that lead to intracellular signaling cascades that switch on or off specific gene expression profiles (Fig. 2). In the following section, some of the major key regulators of muscle fiber type and oxidative phenotype are discussed. A shift in muscle fiber type from type I (slow twitch, oxidative, fatigue resistant) to type II (fast twitch, glycolytic, fatigue prone) fibers has been noted in muscle of patients who have COPD [20].

\section{Peroxisome proliferator-activated receptors}

In the past decade, peroxisome proliferatoractivated receptors (PPARs) have emerged as 


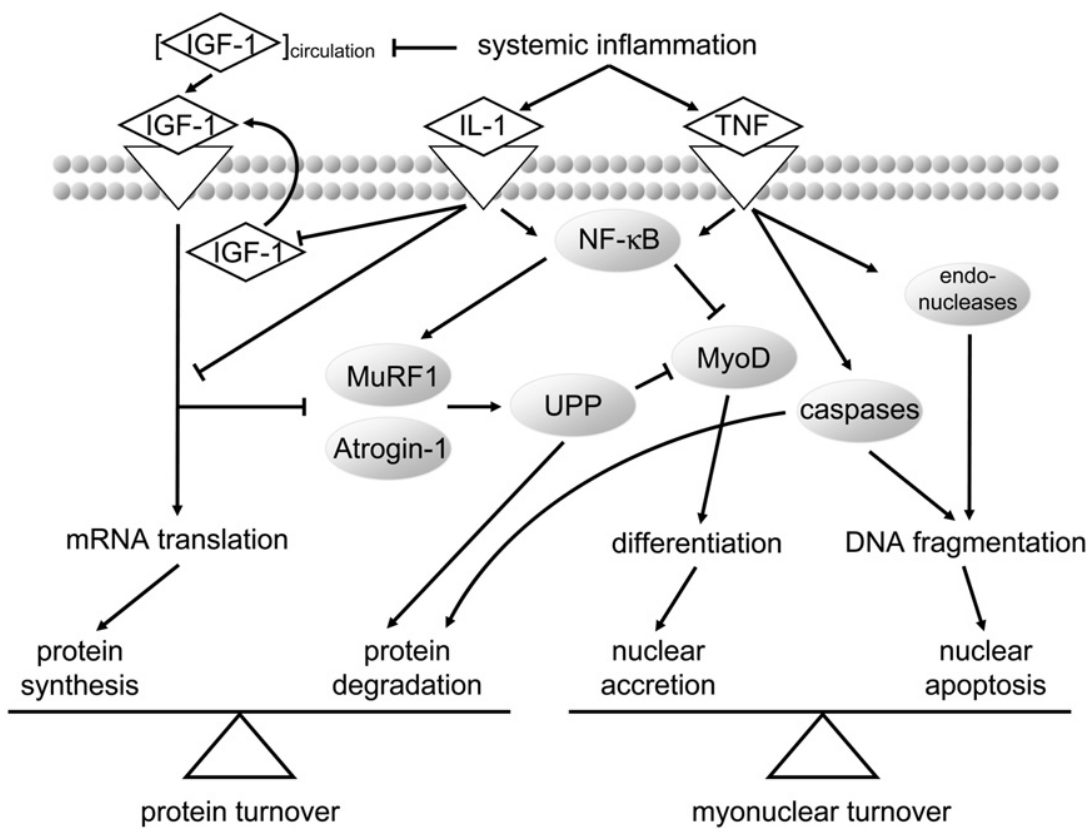

Fig. 1. Schematic overview of the effects of inflammation on regulation of skeletal muscle mass by protein- and myonuclear turnover. Growth factors and cytokines that exert receptor-mediated effects (inverted triangles) are shown as diamonds, intracellular mediators/signaling proteins are displayed as ovals, and intracellular processes are in plain text. Arrows indicate activation, whereas blunted arrows indicate inhibition. IGF-1, insulin growth factor 1; IL-1, interleukin 1; MuRF1, muscle ring finger-1; NF- $\kappa \mathrm{B}$, nuclear factor kappa B; TNF, tumor necrosis factor; UPP, ubiquitin proteasome pathway.

positive regulators of skeletal muscle oxidative phenotype [80,81]. There are three PPAR isotypes: PPAR- $\alpha$, PPAR $-\delta$, and PPAR $-\gamma$, with the latter having a low expression in skeletal muscle and being implicated in storage of fatty acids. On the other hand, the PPAR- $\alpha$ and PPAR- $\delta$ isotypes are highly expressed in skeletal muscle and play a role in the transcriptional control of genes that encode mitochondrial fatty acid $\beta$-oxidation enzymes [80,81]. Many muscle genes that promote selective use of lipid substrates are upregulated by in vivo administration of PPAR- $\alpha$ activators. It has been shown that skeletal muscle PPAR- $\alpha$ protein content is increased by exercise training and is induced during myocyte differentiation, coincident with an increased oxidative capacity $[82,83]$. PPAR- $\alpha$ also regulates fatty acid use and expression of several genes involved in fatty acid $\beta$-oxidation [84]. Based on these results, one would expect that PPAR- $\alpha$ deficiency results in low rates of $\beta$-oxidation in skeletal muscle [85].

Inconsistent with this hypothesis, however, skeletal muscles from PPAR- $\alpha$ knock-out mice exhibited only minor changes in fatty acid homeostasis, and neither constitutive nor inducible expression of known PPAR- $\alpha$ target genes was negatively affected by its absence. Skeletal muscle also expresses high levels of PPAR- $\delta$. Activation of the PPAR- $\delta$ subtype increases fatty acid $\beta$-oxidation and mRNA levels of several classical PPAR- $\alpha$ target genes in rodent and human skeletal muscle cells, and PPAR- $\delta$ protein, like PPAR- $\alpha$ protein, is induced in skeletal muscle after exercise [86]. These results indicate that in addition to PPAR- $\alpha$, PPAR- $\delta$ also plays an important role in mediating lipid-induced regulation of oxidative pathways in skeletal muscle. Because PPAR $-\delta$ is the predominant subtype in skeletal muscle and because isolated rat muscle is more sensitive to a PPAR- $\delta$ - than a PPAR- $\alpha$-specific agonist, a more prominent role for PPAR- $\delta$ in regulating skeletal muscle oxidative capacity has been suggested [87]. Targeted overexpression of PPAR $-\delta$ or a constitutively active form of PPAR- $\delta$ in mouse skeletal muscle results in a greater number of type I oxidative fibers in various muscles. This remodeling was caused by hyperplasia or conversion of fibers to a more oxidative phenotype, similar to what is observed in endurance training [88]. 


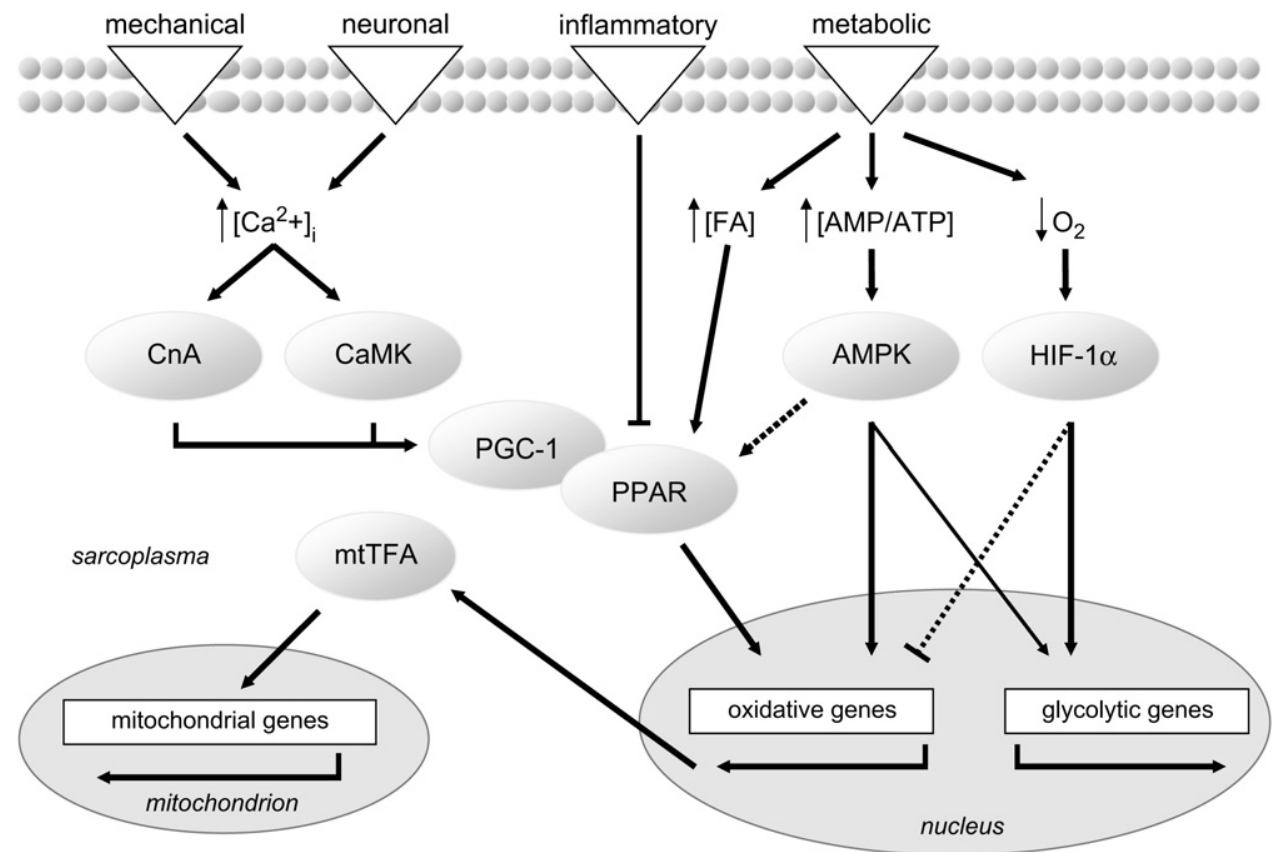

Fig. 2. Schematic overview of muscle oxidative phenotype regulation. Depending on the nature of the stimuli, specific transcriptional pathways are switched on. Arrows indicate activation, whereas blunted arrows indicate inhibition. Dashed arrows indicate less established relationships. FA, fatty acids; CnA, calcineurin; CaMK, calcium/calmodulindependent kinases; AMPK, AMP-activated protein kinase; HIF-1 $\alpha$, hypoxia-inducible factor- $1 \alpha$; PPAR, peroxisome proliferator-activated receptor; PGC-1, PPAR- $\gamma$ coactivator-1; mtTFA, mitochondrial transcriptional factor A.

These histologic observations were confirmed by the finding that muscle-specific PPAR- $\delta$ overexpression led to an increase of oxidative enzymes, such as citrate synthase and $\beta$-hydroxyacylCoA dehydrogenase. Conversely, activities of glycolytic enzymes remained unchanged [88]. These observations were accompanied by the finding that transgenic mice with a constitutively activated form of PPAR- $\delta$ in skeletal muscle were capable of running nearly twice as long as their wild-type littermates without any physical training, which gave functional meaning to these observations. Together, these data strongly support a key role of PPAR- $\alpha$ and PPAR- $\delta$ in the regulation of fatty acid oxidation in skeletal muscle and in the adaptive response of this tissue to lipid catabolism [89].

\section{Peroxisome proliferator-activated receptor- $\gamma$ coactivator- $1 \alpha$}

Probably the master regulator of oxidative phenotype is the peroxisome proliferator-activated receptor- $\gamma$ coactivator-1 (PGC- $1 \alpha)$. Its name is misleading in two ways: it is not just some coactivator secondary to the PPARs, and it is not only a coactivator of PPAR- $\gamma$. PGC- $1 \alpha$ is described most in the context of mitochondrial biogenesis, but it is likely that PGC1- $\beta$ is also somehow involved in the regulation of mitochondrial function [90]. PGC-1 overexpressing muscle cells showed increased mitochondrial respiration, upregulation of genes involved in oxidative phosphorylation, and increased mitochondrial DNA content, all of which indicated enhanced mitochondrial biogenesis [91]. Two key transcription factors in the regulation of mitochondrial function-the nuclear respiratory factor- 1 and the mitochondrial transcription factor $\mathrm{A}-$ were transcriptionally upregulated by PGC-1. Nuclear respiratory factor-1 coordinates the transcription of genes involved in the electron transport chain and that of mitochondrial transcription factor A, which migrates to the mitochondria and initiates transcription of mitochondrial-encoded genes [92]. In transgenic mice that overexpress PGC- $1 \alpha$ in the skeletal muscles, a clear fiber type II $\rightarrow$ I (fast-to-slow) shift was observed, associated with increased mitochondrial gene expression [93]. 


\section{Calcineurin}

An illustrative study for a role of calcineurin in muscle phenotype is that of Talmadge and colleagues [94], which showed that in transgenic mice with muscle-specific overexpression of an active form of calcineurin, the result was a fast-to-slow fiber type shift. Similar results were observed in cultured skeletal myotubes, in which transcription of the slow fiber-specific genes troponin I slow and myoglobin was stimulated by overexpression of active calcineurin. Conversely, administration of cyclosporin $\mathrm{A}$, a calcineurin antagonist, induced a slow-to-fast fiber type shift in rat muscles [95]. Calcium $\left(\mathrm{Ca}^{2+}\right)$ plays an important role in the excitation-relaxation of muscle fibers upon neural activation but also in the regulation of gene expression. The calcineurin-calmodulin complex is activated by binding to $\mathrm{Ca}^{2+}$ and activates the nuclear factor of activated $\mathrm{T}$ cells, which then translocates to the nucleus and switches on slow fiber-specific promoters. It is possible that this is mediated through PGC-1 $\alpha$ [96]. This process preferentially occurs with low frequency or tonic motor nerve activity (typical for slow fibers), which is associated with a sarcolemmal $\mathrm{Ca}^{2+}$-influx $\left([\mathrm{Ca} 2+]_{i}\right)$ of low concentration but of sufficient duration. In contrast, the calcineurin-nuclear factor of activated $\mathrm{T}$ cells pathway is insensitive to shorter high-amplitude $[\mathrm{Ca} 2+]_{i}$ evoked by high frequency motor nerve activity (typical for fast fibers). It is postulated that calcineurin plays an important role in the translation of motor nerve activity patterns into the expression profiles of muscle fiber type-specific genes [95].

\section{Calcium/calmodulin-dependent kinases}

Other pathways by which $\mathrm{Ca}^{2+}$ influences muscle oxidative phenotype are that of the calcium/ calmodulin-dependent kinases (CaMKs): CaMKII and CaMKIV [97]. CaMKIV, when bound to calmodulin- $\mathrm{Ca}^{2+}$, is phosphorylated by CaMK kinase and becomes transcriptionally active. Transgenic mice that overexpress CaMKIV in skeletal muscles showed increased proportions of slow fibers and enhanced mitochondrial biogenesis [98]. In these mice, the increase in mitochondrial content was associated with PGC-1, which suggested that CaMKIV regulates oxidative phenotype through PGC-1. Cultured myocytes that overexpress CaMKIV showed enhanced PGC-1 reporter gene expression [96]. CaMKII also has been suggested to be involved in the regulation of mitochondrial biogenesis [97]. It consists of 12 subunits that become sequentially autophosphorylated the longer CaMKII is bound to calmodulin$\mathrm{Ca}^{2+}$, subsequently associated with an increasing transcriptional activity of CaMKII. Like calcineurin, CaMKII seems to be able to decode stimulation frequencies [97].

\section{AMP-activated protein kinase}

AMP-activated protein kinase (AMPK) plays a critical role in regulating energy metabolism in situations of critical energy demands (eg, as a consequence of exercise) $[99,100]$. Contractioninduced AMPK activity is highest in red muscles, which are largely composed of slow (type I) fibers, compared to white muscle, which contains mostly fast (type II) fibers [101]. Acutely, low-energy status (ie, increased AMP/ATP ratio) activates AMPK, which in turn inhibits ATP-consuming processes and activates substrate metabolism to restore ATP levels. AMPK is also involved in chronic adaptations through regulation of gene expression. However, a broad range of genes involved in energy metabolism have been shown to be controlled by AMPK, most of which are involved in oxidative metabolism, such as components of the Krebs cycle and fatty acid oxidation [99]. It has been demonstrated that chronic energy deprivation enhances AMPK-dependent mitochondrial biogenesis associated with increased protein levels of CaMKIV and PGC-1 $\alpha$ [102], which play an important role in muscle oxidative phenotype.

\section{Hypoxia-inducible factor-1 $\alpha$}

Hypoxia-inducible factor- $1 \alpha$ (HIF- $1 \alpha$ ) mediates numerous adaptations of tissue to hypoxia. Intramuscular partial pressure of oxygen drops during exercise, and increased HIF- $1 \alpha$ protein levels have been reported in muscle from healthy humans after exercise [103]. Likewise, it is possible that this also occurs as a consequence of reduced oxygen supply in diseases such as COPD and chronic heart failure. During normoxia, HIF- $1 \alpha$ is hydroxylated at two proline residues by prolyl-hydroxylases, which promote binding of von Hippel-Lindau protein and target HIF- $1 \alpha$ to degradation by the ubiquitin-proteasome pathway. When oxygen is limited, the prolyl-hydroxylases are inhibited, and HIF-1 $\alpha$ becomes stabilized, migrates to the nucleus, dimerizes with HIF-1 $\beta$, and induces transcription of its target genes [104]. With respect to metabolic profiles, these target genes are mainly genes involved in 
glycolytic metabolism, and HIF- $1 \alpha$ should be regarded as a negative mediator of oxidative capacity [105]. Exposure to hypoxia often induces a shift toward glycolytic metabolism away from oxidative metabolism [106]. Whether HIF-1 $\alpha$ directly downregulates enzymes involved in oxidative metabolism is less obvious, although data from muscle-specific HIF- $1 \alpha$ knock-out mice do support this notion. Recent data also show that the expression of PPARs is inhibited by HIF- $1 \alpha$ [107]. HIF- $1 \alpha$ directly controls muscle oxidative phenotype through regulation of the glycolytic genes and possibly indirectly influences oxidative phenotype via PPAR-dependent pathways.

It is plausible that all of these regulators are to some degree involved in the loss of muscle oxidative phenotype in COPD. Systemic inflammation, a hallmark of COPD, may affect muscle oxidative phenotype by downregulation of the PPARs. It has been shown that a bidirectional antagonism between the PPAR and NF-kB signaling pathway exists. Several studies independently reported that TNF- $\alpha$ and other proinflammatory cytokines under transcriptional control of NF-kB (eg, IL-6)-in vitro and in vivo-exert a downregulating effect on the expression of PPAR mRNAs and have an inhibitory effect on the transcriptional activity of PPAR proteins [108-110]. Remels and colleagues [111] recently demonstrated reduced PPAR levels that correlated negatively with TNF- $\alpha$ levels in the circulation in skeletal muscle of patients who have COPD. The reduced daily physical activity patterns of these patients imply reduced muscular activity, especially endurance related, which could attenuate the expression of oxidative genes through the $\mathrm{Ca}^{2+}$-dependent calcineurin and CaMK pathways or via downregulation of the PPARs [86]. In patients who have COPD, particularly persons who suffer from severe hypoxemia, local hypoxia could cause a shift away from oxidative metabolism through stabilization of HIF$1 \alpha$. Further investigation is needed to understand more fully the spectrum of processes that regulate fiber type shift and loss of muscle oxidative capacity in skeletal muscle of patients who have COPD.

\section{Therapeutic implications}

\section{Modulation of muscle atrophy}

Several studies have investigated the effects of exercise training and pharmacologic anabolic stimuli to promote protein synthesis in patients who have COPD. Resistance exercise [112] and a combined strength and endurance exercise approach [113] resulted in gain of muscle mass. Anabolic steroids, testosterone, growth hormone, and growth hormone-releasing factor also showed a variable but overall positive response on muscle mass [114-116]. These studies illustrated that stimulation of protein synthesis is a feasible therapeutic strategy. No data are available yet regarding the effects of these interventions on muscle IGF-1, mechano growth factor-1 levels, and downstream markers of IGF-1 signaling in COPD. The therapeutic potential of IGF-1 has been reflected mainly by experimental studies in cultured cells and animals, in which stimulation of muscle growth and prevention of aging- or disease-associated muscle loss have been well documented. Recent insights reveal that two distinct cellular processes are involved in postnatal muscle (re)growth: myofiber hypertrophy and muscle regeneration. As a result, the effect of IGF-1 depends on which of these processes participates in the growth response, because IGF-1 signaling differs between muscle cells involved in myofiber hypertrophy and muscle regeneration. Basal IGF-1/insulin signaling is also required for the maintenance of muscle mass by suppression of muscle degradation pathways. It is essential to dissect IGF-1 signal transduction in maintenance of muscle mass and muscle growth responses involving myofiber hypertrophy and regeneration (during the stable clinical state and recovery from acute exacerbations) to identify regulatory molecules as putative candidates for specific pharmacologic modulation of muscle growth and atrophy.

Another yet relatively unexplored possibility for inducing or enhancing muscle weight gain is by nutritional modulation of protein synthesis. Optimizing protein intake may stimulate protein synthesis per se but also may enhance efficacy of anabolic drugs and physiologic stimuli, such as resistance exercise. It has been shown in underweight patients who have COPD that exercise training without nutritional rehabilitation is insufficient to increase weight loss and muscle mass [117]. Amino acids are the building blocks of protein, and several studies have to date reported an abnormal plasma amino acid pattern in COPD. Of interest are the consistently reduced plasma levels of branched chain amino acids in underweight patients who have COPD and in patients with low muscle mass [9]. In particular, leucine is an interesting nutritional substrate because it not only serves as precursor but also activates signaling pathways that enhance activity and synthesis of 
proteins involved in mRNA translocation to upregulate protein synthesis in skeletal muscle [118].

The anabolic response after tailored rehabilitation and pharmacologic stimulation is, however, soon reversed when the anabolic stimulus is terminated. Some patients who have COPD do not respond at all [119]. Muscle wasting in COPD may be the result of a perpetuating systemic inflammatory response, because studies in experimental models have demonstrated cachexiainducing effects of proinflammatory cytokines, such as TNF- $\alpha$, IL-1, and IL-6. Cross-sectional studies provide evidence for inflammation as a trigger of muscle atrophy, and systemic inflammation seemed to discriminate patients with a poor therapeutic response to a standardized and controlled clinical rehabilitation program from so-called "responders" [120]. Because increased levels of multiple inflammatory mediators have been reported in COPD, further work is needed to determine which of these mediators should be targeted to prevent muscle atrophy in patients who have COPD.

From a therapeutic perspective, it would theoretically be more effective to modulate muscle metabolism at a level at which many of these stimuli converge (ie, activation of $\mathrm{NF}-\kappa \mathrm{B}$ in skeletal muscle itself). Evidence to support such a strategy is provided by several recent studies that revealed that NF- $\mathrm{BB}$ activation in skeletal muscle is required for the induction of muscle loss by several atrophy stimuli $[55,56,121]$, and induction of $N F-\kappa B$ specifically in skeletal muscle is sufficient to induce atrophy [55]. Importantly, inactivation of muscular NF- $\kappa \mathrm{B}$ was also documented to stimulate muscle differentiation $[55,75,122]$, promote muscle regeneration, and increase muscle strength [121]. Alternatively, strategies to increase local IGF-1 also may exert inflammatory signaling-suppressive effects [123]. This strategy would positively modulate muscle mass by overcoming the suppressive effects of inflammation on muscle regeneration and stimulation of muscle growth via IGF-1 signaling.

\section{Regulation of muscle metabolism}

Positive effects of pulmonary rehabilitation (particularly endurance exercise training) on oxidative enzymes and exercise capacity illustrate that decreased muscle oxidative capacity in COPD is at least partly reversible [124]. Exercise training also seemed to restore UCP-3 content in limb muscles, especially in patients who showed no increase in hydroxyacylCoA dehydrogenase activity, whereas lipid peroxidation levels were unaltered [125]. The nature of this response complies with the hypothesis that UCP-3 may protect against lipotoxicity (possibly induced or aggravated by oxidative stress) and that antioxidant modulation or fatty acid modulation may positively affect these processes. This may be useful in pulmonary and systemic circumstances that limit high-intensity exercise, such as severe respiratory impairment or cachexia.

A recent report provided evidence for electron transport chain dysfunction of mitochondria in cachectic patients who have COPD and were otherwise characterized by low UCP-3 mRNA expression and abnormal adaptations of skeletal muscle redox status after exercise training $[22,126]$. A recent randomized clinical trial of patients who have COPD participating in a pulmonary rehabilitation program showed that polyunsaturated fatty acids markedly enhanced exercise capacity compared to placebo [127]. These positive effects also could be explained by modulating effects on PPAR content and activity in skeletal muscle, because polyunsaturated fatty acids are natural ligands of the PPARs. Importantly, there is experimental evidence that PPARs also can exert anti-inflammatory effects in airways and muscle cells, thereby not limiting their promising beneficial effects on the pathogenesis of COPD to the extrapulmonary manifestations of the disease but expanding them to the level of the primary organ dysfunction $[128,129]$.

\section{Summary}

Efficacy of known interventions to modulate skeletal muscle function, together with novel insights in the regulation of muscle mass and muscle metabolism as summarized in this article, provides increasing evidence of the need for therapeutic strategies to improve skeletal muscle oxidative capacity and muscle protein synthesis and regulate systemic inflammation and oxidative stress, which are strongly associated with skeletal muscle atrophy and dysfunction in COPD and other chronic disorders.

\section{References}

[1] Agusti AG. Systemic effects of chronic obstructive pulmonary disease. Proc Am Thorac Soc 2005;2: 367-70 [discussion: 71-2]. 
[2] Balasubramanian VP, Varkey B. Chronic obstructive pulmonary disease: effects beyond the lungs. Curr Opin Pulm Med 2006;12:106-12.

[3] Mador MJ. Muscle mass, not body weight, predicts outcome in patients with chronic obstructive pulmonary disease. Am J Respir Crit Care Med 2002;166:787-9.

[4] Gosker HR, Wouters EF, van der Vusse GJ, et al. Skeletal muscle dysfunction in chronic obstructive pulmonary disease and chronic heart failure: underlying mechanisms and therapy perspectives. Am J Clin Nutr 2000;71:1033-47.

[5] Satta A, Migliori GB, Spanevello A, et al. Fibre types in skeletal muscles of chronic obstructive pulmonary disease patients related to respiratory function and exercise tolerance. Eur Respir J 1997;10: 2853-60.

[6] Gosker HR, Engelen MP, van Mameren H, et al. Muscle fiber type IIX atrophy is involved in the loss of fat-free mass in chronic obstructive pulmonary disease. Am J Clin Nutr 2002;76:113-9.

[7] Jagoe RT, Engelen MP. Muscle wasting and changes in muscle protein metabolism in chronic obstructive pulmonary disease. Eur Respir J 2003; 46(Suppl):52s-63s.

[8] Morrison WL, Gibson JN, Scrimgeour C, et al. Muscle wasting in emphysema. Clin Sci (Lond) 1988;75:415-20.

[9] Rutten EP, Franssen FM, Engelen MP, et al. Greater whole-body myofibrillar protein breakdown in cachectic patients with chronic obstructive pulmonary disease. Am J Clin Nutr 2006;83: 829-34.

[10] Agusti AG, Sauleda J, Miralles C, et al. Skeletal muscle apoptosis and weight loss in chronic obstructive pulmonary disease. Am J Respir Crit Care Med 2002;166:485-9.

[11] Gosker HR, Kubat B, Schaart G, et al. Myopathological features in skeletal muscle of patients with chronic obstructive pulmonary disease. Eur Respir J 2003;22:280-5.

[12] Gosker HR, van Mameren H, van Dijk PJ, et al. Skeletal muscle fibre-type shifting and metabolic profile in patients with chronic obstructive pulmonary disease. Eur Respir J 2002;19:617-25.

[13] Jakobsson P, Jorfeldt L, Henriksson J. Metabolic enzyme activity in the quadriceps femoris muscle in patients with severe chronic obstructive pulmonary disease. Am J Respir Crit Care Med 1995; 151:374-7.

[14] Essen-Gustavsson B, Henriksson J. Enzyme levels in pools of microdissected human muscle fibres of identified type: adaptive response to exercise. Acta Physiol Scand 1984;120:505-15.

[15] Pouw EM, Schols AM, van der Vusse GJ, et al. Elevated inosine monophosphate levels in resting muscle of patients with stable chronic obstructive pulmonary disease. Am J Respir Crit Care Med 1998;157:453-7.
[16] Kutsuzawa T, Shioya S, Kurita D, et al. Muscle energy metabolism and nutritional status in patients with chronic obstructive pulmonary disease: a 31P magnetic resonance study. Am J Respir Crit Care Med 1995;152:647-52.

[17] Maltais F, Simard AA, Simard C, et al. Oxidative capacity of the skeletal muscle and lactic acid kinetics during exercise in normal subjects and in patients with COPD. Am J Respir Crit Care Med 1996;153:288-93.

[18] Franssen FM, Broekhuizen R, Janssen PP, et al. Limb muscle dysfunction in COPD: effects of muscle wasting and exercise training. Med Sci Sports Exerc 2005;37:2-9.

[19] Baarends EM, Schols AM, Akkermans MA, et al. Decreased mechanical efficiency in clinically stable patients with COPD. Thorax 1997;52:981-6.

[20] Gosker HR, Schrauwen P, Hesselink MK, et al. Uncoupling protein-3 content is decreased in peripheral skeletal muscle of patients with COPD. Eur Respir J 2003;22:88-93.

[21] Bezaire V, Seifert EL, Harper ME. Uncoupling protein-3: clues in an ongoing mitochondrial mystery. FASEB J 2007;21:312-24.

[22] Rabinovich RA, Ardite E, Troosters T, et al. Reduced muscle redox capacity after endurance training in patients with chronic obstructive pulmonary disease. Am J Respir Crit Care Med 2001;164: 1114-8.

[23] Couillard A, Maltais F, Saey D, et al. Exerciseinduced quadriceps oxidative stress and peripheral muscle dysfunction in patients with chronic obstructive pulmonary disease. Am J Respir Crit Care Med 2003;167:1664-9.

[24] Donaldson GC, Seemungal TA, Patel IS, et al. Airway and systemic inflammation and decline in lung function in patients with COPD. Chest 2005;128: 1995-2004.

[25] Wouters EF, Creutzberg EC, Schols AM. Systemic effects in COPD. Chest 2002;121:127S-30S.

[26] Yanbaeva DG, Dentener MA, Creutzberg EC, et al. Systemic inflammation in COPD: is genetic susceptibility a key factor? COPD 2006;3:51-61.

[27] Pinto-Plata VM, Mullerova H, Toso JF, et al. C-reactive protein in patients with COPD, control smokers and non-smokers. Thorax 2006;61:23-8.

[28] Broekhuizen R, Wouters EF, Creutzberg EC, et al. Raised CRP levels mark metabolic and functional impairment in advanced COPD. Thorax 2006;61: 17-22.

[29] Yende S, Waterer GW, Tolley EA, et al. Inflammatory markers are associated with ventilatory limitation and muscle dysfunction in obstructive lung disease in well functioning elderly subjects. Thorax 2006;61:10-6.

[30] Vernooy JH, Kucukaycan M, Jacobs JA, et al. Local and systemic inflammation in patients with chronic obstructive pulmonary disease: soluble tumor necrosis factor receptors are increased in 
sputum. Am J Respir Crit Care Med 2002;166: 1218-24.

[31] Noguera A, Busquets X, Sauleda J, et al. Expression of adhesion molecules and $G$ proteins in circulating neutrophils in chronic obstructive pulmonary disease. Am J Respir Crit Care Med 1998;158:1664-8.

[32] Takabatake N, Nakamura H, Abe S, et al. The relationship between chronic hypoxemia and activation of the tumor necrosis factor-alpha system in patients with chronic obstructive pulmonary disease. Am J Respir Crit Care Med 2000;161: 1179-84.

[33] Bartoccioni E, Michaelis D, Hohlfeld R. Constitutive and cytokine-induced production of interleukin-6 by human myoblasts. Immunol Lett 1994; 42:135-8.

[34] Tews DS, Goebel HH. Expression of cell adhesion molecules in inflammatory myopathies. J Neuroimmunol 1995;59:185-94.

[35] Langen RC, Schols AM, Kelders MC, et al. Muscle wasting and impaired muscle regeneration in a murine model of chronic pulmonary inflammation. Am J Respir Cell Mol Biol 2006;35:689-96.

[36] Montes de Oca M, Torres SH, De Sanctis J, et al. Skeletal muscle inflammation and nitric oxide in patients with COPD. Eur Respir J 2005;26:390-7.

[37] Agusti A, Morla M, Sauleda J, et al. NF-kappaB activation and iNOS upregulation in skeletal muscle of patients with COPD and low body weight. Thorax 2004;59:483-7.

[38] Broekhuizen R, Grimble RF, Howell WM, et al. Pulmonary cachexia, systemic inflammatory profile, and the interleukin 1 beta -511 single nucleotide polymorphism. Am J Clin Nutr 2005;82: 1059-64.

[39] Buck M, Chojkier M. Muscle wasting and dedifferentiation induced by oxidative stress in a murine model of cachexia is prevented by inhibitors of nitric oxide synthesis and antioxidants. EMBO J 1996; 15:1753-65.

[40] Guttridge DC, Mayo MW, Madrid LV, et al. NFkappaB-induced loss of MyoD messenger RNA: possible role in muscle decay and cachexia. Science 2000;289:2363-6.

[41] Li YP, Schwartz RJ, Waddell ID, et al. Skeletal muscle myocytes undergo protein loss and reactive oxygen-mediated NF-kappaB activation in response to tumor necrosis factor alpha. FASEB J 1998;12:871-80.

[42] Smith BK, Conn CA, Kluger MJ. Experimental cachexia: effects of MCA sarcoma in the Fischer rat. Am J Physiol 1993;265:R376-84.

[43] Pahl HL. Signal transduction from the endoplasmic reticulum to the cell nucleus. Physiol Rev 1999;79:683-701.

[44] Reid MB, Li YP. Tumor necrosis factor-alpha and muscle wasting: a cellular perspective. Respir Res 2001;2:269-72.
[45] Ling PR, Schwartz JH, Bistrian BR. Mechanisms of host wasting induced by administration of cytokines in rats. Am J Physiol 1997;272:E333-9.

[46] Ventadour S, Attaix D. Mechanisms of skeletal muscle atrophy. Curr Opin Rheumatol 2006;18: 631-5.

[47] Li YP, Lecker SH, Chen Y, et al. TNF-alpha increases ubiquitin-conjugating activity in skeletal muscle by up-regulating $\mathrm{UbcH} 2 / \mathrm{E} 220 \mathrm{k}$. FASEB J 2003; 17:1048-57.

[48] Ladner KJ, Caligiuri MA, Guttridge DC. Tumor necrosis factor-regulated biphasic activation of NF-kappa B is required for cytokine-induced loss of skeletal muscle gene products. J Biol Chem 2003;278:2294-303.

[49] Garcia-Martinez C, Llovera M, Agell N, et al. Ubiquitin gene expression in skeletal muscle is increased by tumour necrosis factor-alpha. Biochem Biophys Res Commun 1994;201:682-6.

[50] Gomes MD, Lecker SH, Jagoe RT, et al. Atrogin-1, a muscle-specific F-box protein highly expressed during muscle atrophy. Proc Natl Acad Sci U S A 2001;98:14440-5.

[51] Lecker SH, Jagoe RT, Gilbert A, et al. Multiple types of skeletal muscle atrophy involve a common program of changes in gene expression. FASEB J 2004;18:39-51.

[52] Wray CJ, Mammen JM, Hershko DD, et al. Sepsis upregulates the gene expression of multiple ubiquitin ligases in skeletal muscle. Int $\mathbf{J}$ Biochem Cell Biol 2003;35:698-705.

[53] Drexler H, Riede U, Munzel T, et al. Alterations of skeletal muscle in chronic heart failure. Circulation 1992;85:1751-9.

[54] Inoue I, Katayama S. The possible therapeutic actions of peroxisome proliferator-activated receptor alpha (PPAR alpha) agonists, PPAR gamma agonists, 3-hydroxy-3-methylglutaryl coenzyme A (HMG-CoA) reductase inhibitors, angiotensin converting enzyme (ACE) inhibitors and calcium (Ca)-antagonists on vascular endothelial cells. Curr Drug Targets Cardiovasc Haematol Disord 2004;4:35-52.

[55] Cai D, Frantz JD, Tawa NE Jr, et al. IKKbeta/ NF-kappaB activation causes severe muscle wasting in mice. Cell 2004;119:285-98.

[56] Hunter RB, Kandarian SC. Disruption of either the Nfkb1 or the Bcl3 gene inhibits skeletal muscle atrophy. J Clin Invest 2004;114:1504-11.

[57] Lang CH, Frost RA. Sepsis-induced suppression of skeletal muscle translation initiation mediated by tumor necrosis factor alpha. Metabolism 2007;56: 49-57.

[58] Garcia-Martinez C, Lopez-Soriano FJ, Argiles JM. Acute treatment with tumour necrosis factor-alpha induces changes in protein metabolism in rat skeletal muscle. Mol Cell Biochem 1993;125:11-8.

[59] Lang CH, Frost RA, Nairn AC, et al. TNF-alpha impairs heart and skeletal muscle protein synthesis 
by altering translation initiation. Am J Physiol Endocrinol Metab 2002;282:E336-47.

[60] Cooney RN, Maish GO 3rd, Gilpin T, et al. Mechanism of IL-1 induced inhibition of protein synthesis in skeletal muscle. Shock 1999;11: 235-41.

[61] Thissen JP. How proinflammatory cytokines may impair growth and cause muscle wasting. Horm Res 2007;67(Suppl 1):64-70.

[62] Glass DJ. Skeletal muscle hypertrophy and atrophy signaling pathways. Int J Biochem Cell Biol 2005; 37:1974-84.

[63] Broussard SR, McCusker RH, Novakofski JE, et al. Cytokine-hormone interactions: tumor necrosis factor alpha impairs biologic activity and downstream activation signals of the insulin-like growth factor I receptor in myoblasts. Endocrinology 2003;144:2988-96.

[64] Strle K, Broussard SR, McCusker RH, et al. Proinflammatory cytokine impairment of insulin-like growth factor I-induced protein synthesis in skeletal muscle myoblasts requires ceramide. Endocrinology 2004; 145:4592-602.

[65] Allen DL, Roy RR, Edgerton VR. Myonuclear domains in muscle adaptation and disease. Muscle Nerve 1999;22:1350-60.

[66] Danial NN, Korsmeyer SJ. Cell death: critical control points. Cell 2004;116:205-19.

[67] Almendro V, Carbo N, Busquets S, et al. Sepsis induces DNA fragmentation in rat skeletal muscle. Eur Cytokine Netw 2003;14:256-9.

[68] Phillips T, Leeuwenburgh C. Muscle fiber specific apoptosis and TNF-alpha signaling in sarcopenia are attenuated by life-long calorie restriction. FASEB J 2005; 19:668-70.

[69] Stewart CE, Newcomb PV, Holly JM. Multifaceted roles of TNF-alpha in myoblast destruction: a multitude of signal transduction pathways. J Cell Physiol 2004;198:237-47.

[70] Mitch WE, Du J. Cellular mechanisms causing loss of muscle mass in kidney disease. Semin Nephrol 2004;24:484-7.

[71] Callahan LA, Supinski GS. Diaphragm and cardiac mitochondrial creatine kinases are impaired in sepsis. J Appl Physiol 2007;102:44-53.

[72] Setsuta K, Seino Y, Ogawa T, et al. Ongoing myocardial damage in chronic heart failure is related to activated tumor necrosis factor and Fas/Fas ligand system. Circ J 2004;68:747-50.

[73] van der Velden J, Langen R, Kelders M, et al. Myogenic differentiation during regrowth of atrophied skeletal muscle is associated with inactivation of GSK-3 beta\}. Am J Physiol Cell Physiol 2007; 292(5):C1636-44.

[74] Hawke TJ, Garry DJ. Myogenic satellite cells: physiology to molecular biology. J Appl Physiol 2001;91:534-51.

[75] Langen RC, Schols AM, Kelders MC, et al. Inflammatory cytokines inhibit myogenic differentiation through activation of nuclear factor-kappaB. FASEB J 2001;15:1169-80.

[76] Dogra C, Changotra H, Wedhas N, et al. TNFrelated weak inducer of apoptosis (TWEAK) is a potent skeletal muscle-wasting cytokine. FASEB J 2007;21(8):1857-69.

[77] Broussard SR, McCusker RH, Novakofski JE, et al. IL-1beta impairs insulin-like growth factor i-induced differentiation and downstream activation signals of the insulin-like growth factor i receptor in myoblasts. J Immunol 2004;172:7713-20.

[78] Langen RC, Van Der Velden JL, Schols AM, et al. Tumor necrosis factor-alpha inhibits myogenic differentiation through MyoD protein destabilization. FASEB J 2004;18:227-37.

[79] Tolosa L, Morla M, Iglesias A, et al. IFN-gamma prevents TNF-alpha-induced apoptosis in $\mathrm{C} 2 \mathrm{C} 12$ myotubes through down-regulation of TNF-R2 and increased NF-kappaB activity. Cell Signal 2005; 17:1333-42.

[80] Fredenrich A, Grimaldi PA. Roles of peroxisome proliferator-activated receptor delta in skeletal muscle function and adaptation. Curr Opin Clin Nutr Metab Care 2004;7:377-81.

[81] Lefebvre P, Chinetti G, Fruchart JC, et al. Sorting out the roles of PPAR alpha in energy metabolism and vascular homeostasis. J Clin Invest 2006;116: 571-80.

[82] Cresci S, Wright LD, Spratt JA, et al. Activation of a novel metabolic gene regulatory pathway by chronic stimulation of skeletal muscle. Am J Physiol 1996;270:C1413-20.

[83] Horowitz JF, Leone TC, Feng W, et al. Effect of endurance training on lipid metabolism in women: a potential role for PPARalpha in the metabolic response to training. Am J Physiol Endocrinol Metab 2000;279:E348-55.

[84] Minnich A, Tian N, Byan L, et al. A potent PPARalpha agonist stimulates mitochondrial fatty acid beta-oxidation in liver and skeletal muscle. Am J Physiol Endocrinol Metab 2001;280:E270-9.

[85] Muoio DM, MacLean PS, Lang DB, et al. Fatty acid homeostasis and induction of lipid regulatory genes in skeletal muscles of peroxisome proliferator-activated receptor (PPAR) alpha knock-out mice: evidence for compensatory regulation by PPAR delta. J Biol Chem 2002;277:26089-97.

[86] Fritz T, Kramer DK, Karlsson HK, et al. Lowintensity exercise increases skeletal muscle protein expression of PPARdelta and UCP3 in type 2 diabetic patients. Diabetes Metab Res Rev 2006;22:492-8.

[87] Brunmair B, Staniek K, Dorig J, et al. Activation of PPAR-delta in isolated rat skeletal muscle switches fuel preference from glucose to fatty acids. Diabetologia 2006;49:2713-22.

[88] Luquet S, Lopez-Soriano J, Holst D, et al. Peroxisome proliferator-activated receptor delta controls muscle development and oxidative capability. FASEB J 2003;17:2299-301. 
[89] Furnsinn C, Willson TM, Brunmair B. Peroxisome proliferator-activated receptor-delta, a regulator of oxidative capacity, fuel switching and cholesterol transport. Diabetologia 2007;50:8-17.

[90] St-Pierre J, Lin J, Krauss S, et al. Bioenergetic analysis of peroxisome proliferator-activated receptor gamma coactivators 1alpha and 1beta (PGC-1alpha and PGC-1beta) in muscle cells. J Biol Chem 2003;278:26597-603.

[91] Wu Z, Puigserver P, Andersson U, et al. Mechanisms controlling mitochondrial biogenesis and respiration through the thermogenic coactivator PGC-1. Cell 1999;98:115-24.

[92] Scarpulla RC. Nuclear activators and coactivators in mammalian mitochondrial biogenesis. Biochim Biophys Acta 2002;1576:1-14.

[93] Lin J, Wu H, Tarr PT, et al. Transcriptional coactivator PGC-1 alpha drives the formation of slowtwitch muscle fibres. Nature 2002;418:797-801.

[94] Talmadge RJ, Otis JS, Rittler MR, et al. Calcineurin activation influences muscle phenotype in a muscle-specific fashion. BMC Cell Biol 2004;5:28.

[95] Chin ER, Olson EN, Richardson JA, et al. A calcineurin-dependent transcriptional pathway controls skeletal muscle fiber type. Genes Dev 1998;12: 2499-509.

[96] Handschin C, Rhee J, Lin J, et al. An autoregulatory loop controls peroxisome proliferator-activated receptor gamma coactivator lalpha expression in muscle. Proc Natl Acad Sci U S A 2003;100:7111-6.

[97] Chin ER. Role of Ca2+/calmodulin-dependent kinases in skeletal muscle plasticity. J Appl Physiol 2005;99:414-23.

[98] Wu H, Kanatous SB, Thurmond FA, et al. Regulation of mitochondrial biogenesis in skeletal muscle by CaMK. Science 2002;296:349-52.

[99] Aschenbach WG, Sakamoto K, Goodyear LJ. 5' adenosine monophosphate-activated protein kinase, metabolism and exercise. Sports Med 2004; 34:91-103.

[100] Reznick RM, Shulman GI. The role of AMP-activated protein kinase in mitochondrial biogenesis. J Physiol 2006;574:33-9.

[101] Ai H, Ihlemann J, Hellsten Y, et al. Effect of fiber type and nutritional state on AICAR- and contraction-stimulated glucose transport in rat muscle. Am J Physiol Endocrinol Metab 2002;282: E1291-300.

[102] Zong H, Ren JM, Young LH, et al. AMP kinase is required for mitochondrial biogenesis in skeletal muscle in response to chronic energy deprivation. Proc Natl Acad Sci U S A 2002;99:15983-7.

[103] Ameln H, Gustafsson T, Sundberg CJ, et al. Physiological activation of hypoxia inducible factor- 1 in human skeletal muscle. FASEB J 2005;19:1009-11.

[104] Semenza GL. HIF-1, O(2), and the 3 PHDs: how animal cells signal hypoxia to the nucleus. Cell 2001;107:1-3.
[105] Semenza GL. HIF-1: mediator of physiological and pathophysiological responses to hypoxia. J Appl Physiol 2000;88:1474-80.

[106] Hoppeler H, Vogt M. Muscle tissue adaptations to hypoxia. J Exp Biol 2001;204:3133-9.

[107] Narravula S, Colgan SP. Hypoxia-inducible factor 1-mediated inhibition of peroxisome proliferatoractivated receptor alpha expression during hypoxia. J Immunol 2001;166:7543-8.

[108] Delerive P, De Bosscher K, Besnard S, et al. Peroxisome proliferator-activated receptor alpha negatively regulates the vascular inflammatory gene response by negative cross-talk with transcription factors NF-kappaB and AP-1. J Biol Chem 1999; 274:32048-54.

[109] Sung CK, She H, Xiong S, et al. Tumor necrosis factor-alpha inhibits peroxisome proliferator-activated receptor gamma activity at a posttranslational level in hepatic stellate cells. Am J Physiol Gastrointest Liver Physiol 2004; 286:G722-9.

[110] Tham DM, Martin-McNulty B, Wang YX, et al. Angiotensin II is associated with activation of NF-kappaB-mediated genes and downregulation of PPARs. Physiol Genomics 2002;11:21-30.

[111] Remels AH, Schrauwen P, Broekhuizen R, et al. Expression and contents of PPARs is reduced in skeletal muscles of COPD patients. Eur Respir J 2007;30(2).

[112] Bernard S, Whittom F, Leblanc P, et al. Aerobic and strength training in patients with chronic obstructive pulmonary disease. Am J Respir Crit Care Med 1999;159:896-901.

[113] Franssen FM, Broekhuizen R, Janssen PP, et al. Effects of whole-body exercise training on body composition and functional capacity in normalweight patients with COPD. Chest 2004;125: 2021-8.

[114] Casaburi R. Anabolic therapies in chronic obstructive pulmonary disease. Monaldi Arch Chest Dis 1998;53:454-9.

[115] Creutzberg EC, Casaburi R. Endocrinological disturbances in chronic obstructive pulmonary disease. Eur Respir J 2003;46(Suppl):76s-80s.

[116] Ferreira I, Brooks D, Lacasse Y, et al. Nutritional intervention in COPD: a systematic overview. Chest 2001;119:353-63.

[117] Schols AM, Soeters PB, Mostert R, et al. Physiologic effects of nutritional support and anabolic steroids in patients with chronic obstructive pulmonary disease: a placebo-controlled randomized trial. Am J Respir Crit Care Med 1995;152: 1268-74.

[118] Anthony JC, Anthony TG, Kimball SR, et al. Signaling pathways involved in translational control of protein synthesis in skeletal muscle by leucine. J Nutr 2001;131:856S-60S.

[119] Bolton CE, Broekhuizen R, Ionescu AA, et al. Cellular protein breakdown and systemic 
inflammation are unaffected by pulmonary rehabilitation in COPD. Thorax 2007;62:109-14.

[120] Creutzberg EC, Schols AM, Weling-Scheepers CA, et al. Characterization of nonresponse to high caloric oral nutritional therapy in depleted patients with chronic obstructive pulmonary disease. Am J Respir Crit Care Med 2000;161:745-52.

[121] Mourkioti F, Kratsios P, Luedde T, et al. Targeted ablation of IKK2 improves skeletal muscle strength, maintains mass, and promotes regeneration. J Clin Invest 2006;116:2945-54.

[122] Guttridge DC, Albanese C, Reuther JY, et al. NF-kappaB controls cell growth and differentiation through transcriptional regulation of cyclin D1. Mol Cell Biol 1999;19:5785-99.

[123] Pelosi L, Giacinti C, Nardis C, et al. Local expression of IGF-1 accelerates muscle regeneration by rapidly modulating inflammatory cytokines and chemokines. FASEB J 2007;21(7): 1393-402.

[124] Puente-Maestu L, Tena T, Trascasa C, et al. Training improves muscle oxidative capacity and oxygenation recovery kinetics in patients with chronic obstructive pulmonary disease. Eur J Appl Physiol 2003;88:580-7.

[125] Gosker HR, Schrauwen P, Broekhuizen R, et al. Exercise training restores uncoupling protein-3 content in limb muscles of patients with chronic obstructive pulmonary disease. Am J Physiol Endocrinol Metab 2006;290(5):E976-81.

[126] Rabinovich RA, Bastos R, Ardite E, et al. Mitochondrial dysfunction in COPD patients with low body mass index. Eur Respir J 2007;29:643-50.

[127] Broekhuizen R, Wouters EF, Creutzberg EC, et al. Polyunsaturated fatty acids improve exercise capacity in chronic obstructive pulmonary disease. Thorax 2005;60:376-82.

[128] Birrell MA, Patel HJ, McCluskie K, et al. PPARgamma agonists as therapy for diseases involving airway neutrophilia. Eur Respir J 2004;24:18-23.

[129] Patel HJ, Belvisi MG, Bishop-Bailey D, et al. Activation of peroxisome proliferator-activated receptors in human airway smooth muscle cells has a superior anti-inflammatory profile to corticosteroids: relevance for chronic obstructive pulmonary disease therapy. J Immunol 2003;170:2663-9. 